\title{
A Comparison of Mortality following Distal Femoral Fractures and Hip Fractures in an Elderly Population
}

\author{
R. W. Jordan, ${ }^{1}$ G. S. Chahal, ${ }^{1}$ M. Davies, ${ }^{2}$ and K. Srinivas ${ }^{1}$ \\ ${ }^{1}$ Birmingham Heartlands Hospital, Bordesley Green East, Birmingham B9 5SS, UK \\ ${ }^{2}$ Worcester Royal Hospital, Charles Hastings Way, Worcester WR5 1DD, UK \\ Correspondence should be addressed to R. W. Jordan; robert.jordan@doctors.org.uk
}

Received 1 June 2014; Revised 13 July 2014; Accepted 22 July 2014; Published 7 August 2014

Academic Editor: Werner Kolb

Copyright (C) 2014 R. W. Jordan et al. This is an open access article distributed under the Creative Commons Attribution License, which permits unrestricted use, distribution, and reproduction in any medium, provided the original work is properly cited.

\begin{abstract}
Introduction. Patients suffering a distal femoral fracture are at a high risk of morbidity and mortality. Currently this cohort is not afforded the same resources as those with hip fractures. This study aims to compare their mortality rates and assess whether surgical intervention improves either outcome or mortality following distal femoral fractures. Methods. Patients over sixty-five admitted with a distal femoral fracture between June 2007 and 2012 were retrospectively identified. Patients mobility was categorised as unaided, walking aid, zimmer frame, or immobile. The 30-day, six-month, and one-year mortality rates were recorded for this group as well as for hip fractures during the same period. Results. 68 patients were included in the study. The mortality rate for all patients with distal femoral fractures was $7 \%$ at 30 days, $26 \%$ at six months, and $38 \%$ at one year, higher than hip fractures during the same period by $8 \%, 13 \%$, and $18 \%$, respectively. Patients managed surgically had lower mortality rates and higher mobility levels. Conclusion. Patients suffering a distal femoral fracture have a high mortality rate and surgical intervention seems to improve both mobility and mortality.
\end{abstract}

\section{Introduction}

Distal femoral fractures can result from either high energy injuries in young adults or low energy injuries in elderly patients with osteoporotic bone [1-3]. This injury accounts for around 6\% of all fragility fractures [3] and its frequency is likely to rise with the increasing geriatric population. The prevalence of periprosthetic fractures following knee arthroplasty is $0.5 \%-2.2 \%[4,5]$ which is also likely to increase with the rise in arthroplasties being performed [6].

Patients suffering a distal femoral fracture are at a high risk of complication given the prevalence of medical comorbidities in this cohort [7-9]. The mortality rates have been reported to be around $18 \%$ at six months and $18-30 \%$ at one year $[1,2,10,11]$. The presence of either a knee arthroplasty or a significant comorbidity is associated with an increased mortality [2]. The injury has a significant effect on patients' mobility with one series reporting only $18 \%$ were able to walk unaided with $23 \%$ housebound and $26 \%$ not able to perform social activities [12].

Traditionally traction followed by cast bracing was the common treatment technique [13]; however this option results in prolonged bed rest [14], loss of motion [15, 16], and either nonunion or malunion [17]. Butt et al. performed a randomised controlled trial comparing six weeks of traction followed by bracing with plate fixation. The authors reported good or excellent results in 53\% of the surgical group and only $31 \%$ of the nonoperative group. The nonoperative group also had a longer hospital stay and a higher complication rate [11]. The aims of surgery are to restore articular congruency and alignment. The use of both intramedullary nails [18-20] and locking plates $[2,3,21-24]$ has been shown to have good results. Locking plates allow load to be evenly distributed amongst all screws avoiding loading on single screw and this may be preferable in osteoporotic bone [25]. However reports suggest that locking plates are associated with a higher complication rate $[26,27]$ : nonunion $(5.5 \%$ versus $5 \%)$, fixation failure (4.9\% versus $3 \%)$, and infection ( $2.1 \%$ versus $0.4 \%)[1,26,28]$. The presence of either an ipsilateral knee or hip arthroplasty may limit the use of intramedullary devices and needs to be considered when planning surgery.

Hip fractures occur in a similarly elderly and at risk group of patients. The number of hip fractures between April 2012 
and March 2013 in the UK was 61,508 patients, the mean length of stay was 20 days, and the 30 -day mortality rate was $8.2 \%$ [29]. One-year mortality has been separately reported at $20 \%[30,31]$. This high mortality is probably due to a combination of trauma, major surgery, and concurrent medical problems [30]. The hip fracture cohort has received prioritisation and funding in the National Health Service (NHS) in the UK with the recent implementation of the "best practice tariff." This tariff provides financial incentive to hospitals for successfully achieving six criteria which aim to drive up the quality of care, admission to orthopaedic ward within 4 hours, surgery within 48 hours, monitoring for pressure ulcers, preoperative assessment by an orthogeriatrician, discharge on bone protection medication, and a falls assessment prior to discharge.

The aim of this study, for the first time, is to compare the mortality rates between hip and distal femoral fracture patients in one centre. In addition, the study aims to assess whether the outcome or mortality is improved when distal femoral fractures are managed either surgically or nonoperatively.

\section{Methods}

All patients over the age of sixty-five admitted with a distal third femoral fracture between June 2007 and June 2012 were retrospectively identified. Pathological fractures and those resulting from high velocity trauma were excluded from the study. High velocity trauma was defined as a pedestrian hit by a vehicle, high speed road traffic collision (combined velocity $>40 \mathrm{mph}$ ), ejection from vehicle, fatality in the same vehicle, or fall from a significant height ( $>5$ metres). Electronic records were analysed for patient demographics, the presence of a knee arthroplasty, and whether the patient underwent nonoperative or surgical treatment with either plate fixation or intramedullary nailing. Patients were followed up regarding their mobility categorised as unaided, walking aid, zimmer frame, and immobile. The 30-day, six-month, and one-year mortality rates were recorded. The mean follow-up was 3.2 years (range 1 to 5 years).

In addition, all patients over the age of sixty-five admitted during the same time period with a hip fracture were also identified. For this group no exclusion criteria were applied. The 30-day, six-month, and one-year mortality rates were also recorded for this group.

\section{Results}

During the study 74 patients were treated for a distal femoral fracture. Six patients were excluded, two due to a pathological fracture and four due to high energy mechanism of injury. 30 patients were excluded from mobility analysis as they either received no follow-up or died during the first-year period. $58(85 \%)$ of the patients were female, the mean age was 84 years, and $8(12 \%)$ had periprosthetic fractures. 43 patients $(63 \%)$ were managed nonoperatively and of those treated surgically 7 had plate fixation (28\%) and 18 had intramedullary nailing (72\%). The demographics for these separate groups is illustrated in Table 1.
TABle 1: Patient demographics according to treatment received.

\begin{tabular}{|c|c|c|c|}
\hline & Conservative & Plate fixation & $\begin{array}{c}\text { Intramedullary } \\
\text { nail }\end{array}$ \\
\hline Number & 43 & 7 & 18 \\
\hline Mean age (years) & 84 & 77 & 87 \\
\hline $\begin{array}{l}\text { Female } \\
N(\%)\end{array}$ & $38(88)$ & $6(86)$ & $16(83)$ \\
\hline $\begin{array}{l}\text { Knee arthroplasty } \\
N(\%)\end{array}$ & $6(14)$ & $1(14)$ & $1(6)$ \\
\hline
\end{tabular}

TABLE 2: Mortality rate according to treatment received.

\begin{tabular}{lcccc}
\hline Mortality & Nonoperative & Surgery & $\begin{array}{c}\text { Intramedullary } \\
\text { nail }\end{array}$ & $\begin{array}{c}\text { Plate } \\
\text { fixation }\end{array}$ \\
\hline $\begin{array}{l}30 \text { days } \\
N(\%)\end{array}$ & $4(9)$ & $1(4)$ & $1(6)$ & $0(0)$ \\
6 months & $14(33)$ & $5(20)$ & $4(22)$ & $1(14)$ \\
$\begin{array}{l}N(\%) \\
1 \text { year }\end{array}$ & $20(47)$ & $7(28)$ & $5(28)$ & $2(29)$ \\
$N(\%)$ & & & & \\
\hline
\end{tabular}

The mortality rate for all patients with distal femoral fractures was $7 \%$ (5 patients) at 30 days, $26 \%$ (18 patients) at six months, and $38 \%$ (26 patients) at one year. During the same study period there were 2,327 hip fractures and the mortality rates were $8 \%$ at 30 days, $13 \%$ at six months, and $18 \%$ at one year. The comparison between the two groups is illustrated in Figure 1. Those patients managed surgically had lower mortality rates (Table 2 ).

Only 38 of patients $(56 \%)$ had data available for mobility at follow-up over one year, 26 patients (38\%) had died during this period, and 2 patients (6\%) received no formal follow-up and therefore data was not available. Comparison of mobility between the surgically and nonoperatively managed groups is demonstrated in Figure 2.

\section{Discussion}

Patients suffering a distal femoral fracture are a high risk group and the authors report a $38 \%$ mortality rate at one year. This value is higher than those reported in the literature $[1,2,10,11]$ and maybe a reflection of the high number of patients managed nonoperatively. To allow for direct comparisons between studies further information regarding the comorbidities is required and due to the retrospective nature of the study this was not feasible.

Those patients managed surgically had better outcomes in terms of mobility (immobility $21 \%$ after nonoperative treatment versus 5\% after surgical intervention) and mortality ( $47 \%$ versus $28 \%$ ). Although categorised differently this mobility was at least comparable to that reported in the literature [12]. Surgical intervention allows for earlier knee movement and mobilisation, aids nursing care, and facilitates an earlier discharge, and this may explain the improved outcomes in this group. Therefore focus should be on early surgical intervention to aid patient recovery and achieve the optimal outcome. Previous reports in hip fracture patients have 


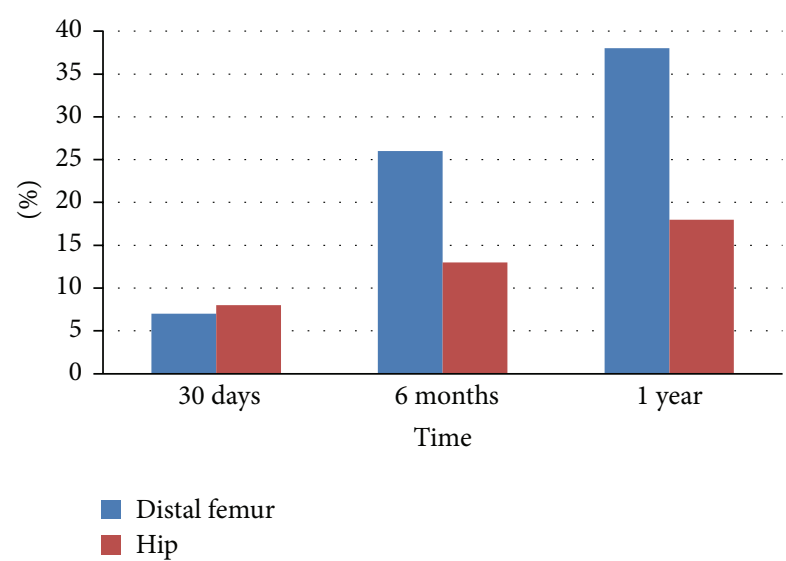

FIGURE 1: Comparison of mortality between distal femur and hip fracture patients.

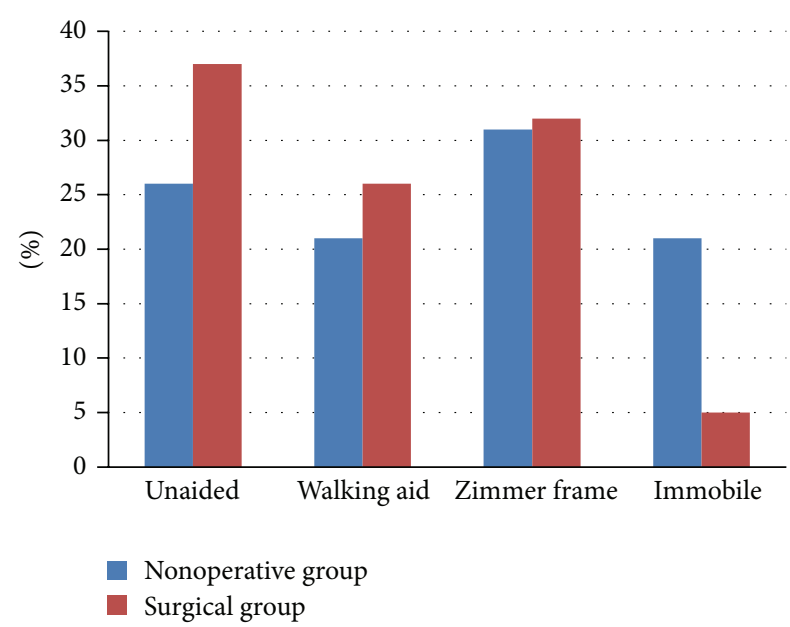

FIGURE 2: Comparison of mortality between surgical and nonoperative group.

shown that a delay to surgery can increase mortality rates [32]. The number in the current study is too small to test whether a delay to surgery negatively impacted on patient outcomes but this seems feasible and further work to address question is required.

The results show that patients with distal femoral fractures had a worse outcome than their hip fracture counterparts in terms of mortality over the same time period. Further details regarding the distribution of comorbidities would have improved this comparison but this finding is supported by figures from the literature [29-31]. A multidisciplinary approach to hip fractures has been shown to be beneficial [33-35] and application of these principles to distal femoral fracture patients seems logical and has the potential to reduce both morbidity and mortality. However the authors must stress that the incidence of distal femoral fractures over the study period was 34 times lower than hip fractures and therefore the absolute mortality numbers were actually much higher in the hip fracture group.
The study had some limitations, the main one being its retrospective nature with data collection being limited to that routinely recorded in patient notes. Further information regarding patient comorbidities, previous ambulatory status, and cognition would have provided important information to aid comparison of the groups. A validated patient reported outcome would have given a patient's perspective on the success of treatment but these were not routinely recorded. The distal femoral fracture group contained only 68 patients compared to 2,327 in the hip fracture group; this small study group could have substantially affected the mortality rate observed. The considerably higher incidence of hip fractures has previously been reported in the literature $[1,9]$; despite the higher percentage mortality in the distal femur group, the absolute number of deaths in the hip fracture group is significantly higher. The data included were from a single centre and may not be universally representative of all patients. However the paper does have two key messages: firstly that these patients are a high risk group with worse outcomes than their hip fracture counterparts and secondly that surgery seems to improve outcome and early intervention should be targeted.

\section{Conclusion}

Patients suffering a distal femoral fracture have a high mortality rate and surgical intervention seems to improve both mobility and mortality. Further research assessing a multidisciplinary approach to managing this cohort is required.

\section{Conflict of Interests}

The authors declare that there is no conflict of interests regarding the publication of this paper.

\section{References}

[1] O. Martinet, J. Cordey, Y. Harder, A. Maier, M. Bühler, and G. E. Barraud, "The epidemiology of fractures of the distal femur," Injury, vol. 31, supplement 3, pp. C62-C63, 2000.

[2] P. N. Streubel, W. M. Ricci, A. Wong, and M. J. Gardner, "Mortality after distal femur fractures in elderly patients," Clinical Orthopaedics and Related Research, vol. 469, no. 4, pp. 1188-1196, 2011.

[3] F. W. Gwathmey Jr., S. M. Jones-Quaidoo, D. Kahler, S. Hurwitz, and Q. Cui, "Distal femoral fractures: current concepts," Journal of the American Academy of Orthopaedic Surgeons, vol. 18, no. 10, pp. 597-607, 2010.

[4] D. C. Ayers, D. A. Dennis, N. A. Johanson, and J. V. D. Pellegrini, "Instructional course lectures. The American Academy of Orthopaedic Surgeons-common complications of total knee arthroplasty," Journal of Bone and Joint Surgery, vol. 79, no. 2, pp. 278-311, 1997.

[5] R. M. D. Meek, T. Norwood, R. Smith, I. J. Brenkel, and C. R. Howie, "The risk of peri-prosthetic fracture after primary and revision total hip and knee replacement," Journal of Bone and Joint Surgery B, vol. 93, no. 1, pp. 96-101, 2011.

[6] J. Parvizi, N. Jain, and A. H. Schmidt, "Periprosthetic knee fractures," Journal of Orthopaedic Trauma, vol. 22, no. 9, pp. 663671, 2008. 
[7] A. D. Boyd Jr. and J. H. Wilber, "Patterns and complications of femur fractures below the hip in patients over 65 years of age," Journal of Orthopaedic Trauma, vol. 6, no. 2, pp. 167-174, 1992.

[8] A. Christodoulou, I. Terzidis, A. Ploumis, S. Metsovitis, A. Koukoulidis, and C. Toptsis, "Supracondylar femoral fractures in elderly patients treated with the dynamic condylar screw and the retrograde intramedullary nail: a comparative study of the two methods," Archives of Orthopaedic and Trauma Surgery, vol. 125, no. 2, pp. 73-79, 2005.

[9] J. W. Nieves, J. P. Bilezikian, J. M. Lane et al., "Fragility fractures of the hip and femur: incidence and patient characteristics," Osteoporosis International, vol. 21, no. 3, pp. 399-408, 2010.

[10] M. S. Butt, S. J. Krikler, and M. S. Ali, "Displaced fractures of the distal femur in elderly patients," Journal of Bone and Joint Surgery B, vol. 78, no. 1, pp. 110-114, 1996.

[11] D. G. Dunlop and I. J. Brenkel, "The supracondylar intramedullary nail in elderly patients with distal femoral fractures," Injury, vol. 30, no. 7, pp. 475-484, 1999.

[12] C. Kammerlander, P. Riedmüller, M. Gosch et al., "Functional outcome and mortality in geriatric distal femoral fractures," Injury, vol. 43, no. 7, pp. 1096-1101, 2012.

[13] J. F. Connolly, E. Dehne, and B. Lafollette, "Closed reduction and early cast brace ambulation in the treatment of femoral fractures. Part II: results in one hundred and forty three fractures," Journal of Bone and Joint Surgery A, vol. 55, no. 8, pp. 1581-1599, 1973.

[14] M. Stover, "Distal femoral fractures: current treatment, results and problems," Injury, vol. 32, supplement 3, pp. C3-C13, 2001.

[15] D. A. Dennis, "Periprosthetic fractures following total knee arthroplasty," Journal of Bone and Joint Surgery A, vol. 83, no. 1, pp. 120-130, 2001.

[16] M. C. Moran, G. W. Brick, C. B. Sledge, S. H. Dysart, and E. P. Chien, "Supracondylar femoral fracture following total knee arthroplasty," Clinical Orthopaedics and Related Research, vol. 324, pp. 196-209, 1996.

[17] R. W. Culp, R. G. Schmidt, G. Hanks, A. Mak, J. L. Esterhai Jr., and R. B. Heppenstall, "Supracondylar fracture of the femur following prosthetic knee arthroplasty," Clinical Orthopaedics and Related Research, no. 222, pp. 212-222, 1987.

[18] A. Kumar, V. Jasani, and M. S. Butt, "Management of distal femoral fractures in elderly patients using retrograde titanium supracondylar nails," Injury, vol. 31, no. 3, pp. 169-173, 2000.

[19] J. B. Gynning and D. Hansen, "Treatment of distal femoral fractures with intramedullary supracondylar nails in elderly patients," Injury, vol. 30, no. 1, pp. 43-46, 1999.

[20] R. Armstrong, A. Milliren, W. Schrantz, and K. Zeliger, "Retrograde interlocked intramedullary nailing of supracondylar distal femur fractures in an average 76-year-old patient population," Orthopedics, vol. 26, no. 6, pp. 627-629, 2003.

[21] R. E. Anakwe, S. A. Aitken, and L. A. K. Khan, "Osteoporotic periprosthetic fractures of the femur in elderly patients: outcome after fixation with the LISS plate," Injury, vol. 39, no. 10, pp. 1191-1197, 2008.

[22] W. M. Ricci, T. Loftus, C. Cox, and J. Borrelli, "Locked plates combined with minimally invasive insertion technique for the treatment of periprosthetic supracondylar femur fractures above a total knee arthroplasty," Journal of Orthopaedic Trauma, vol. 20, no. 3, pp. 190-196, 2006.

[23] P. Platzer, R. Schuster, S. Aldrian et al., "Management and outcome of periprosthetic fractures after total knee arthroplasty," The Journal of Trauma, vol. 68, no. 6, pp. 1464-1470, 2010.
[24] M. F. Hoffmann, C. B. Jones, D. L. Sietsema, S. J. Koenig, and P. Tornetta III, "Outcome of periprosthetic distal femoral fractures following knee arthroplasty," Injury, vol. 43, no. 7, pp. 1084-1089, 2012.

[25] E. J. Strauss, R. Schwarzkopf, F. Kummer, and K. A. Egol, “The current status of locked plating: the good, the bad, and the ugly," Journal of Orthopaedic Trauma, vol. 22, no. 7, pp. 479-486, 2008.

[26] M. Zlowodzki, M. Bhandari, D. J. Marek, P. A. Cole, and P. J. Kregor, "Operative treatment of acute distal femur fractures: systematic review of 2 comparative studies and 45 case series (1989 to 2005)," Journal of Orthopaedic Trauma, vol. 20, no. 5, pp. 366-371, 2006.

[27] N. L. Hartin, I. Harris, and K. Hazratwala, "Retrograde nailing versus fixed-angle blade plating for supracondylar femoral fractures: a randomized controlled trial," ANZ Journal of Surgery, vol. 76, no. 5, pp. 290-294, 2006.

[28] K. S. Leung, W. Y. Shen, W. S. So, L. T. Mui, and A. Grosse, "Interlocking intramedullary nailing for supracondylar and intercondylar fractures of the distal part of the femur," Journal of Bone and Joint Surgery A, vol. 73, no. 3, pp. 332-340, 1991.

[29] National Hip Fracture Database, "National Hip Fracture Database National Report 2013," http://www.nhfd.co.uk/.

[30] J. E. Kenzora, R. E. McCarthy, J. D. Lowell, and C. B. Sledge, "Hip fracture mortality. Relation to age, treatment, preoperative illness, time of surgery, and complications," Clinical Orthopaedics and Related Research, vol. 186, pp. 45-56, 1984.

[31] G. S. Keene, M. J. Parker, and G. A. Pryor, "Mortality and morbidity after hip fractures," BMJ, vol. 307, pp. 1248-1250, 1993.

[32] A. Bottle and P. Aylin, "Mortality associated with delay in operation after hip fracture: observational study," British Medical Journal, vol. 332, no. 7547, pp. 947-950, 2006.

[33] S. M. Friedman, D. A. Mendelson, K. W. Bingham, and S. L. Kates, "Impact of a comanaged geriatric fracture center on short-term hip fracture outcomes," Archives of Internal Medicine, vol. 169, no. 18, pp. 1712-1717, 2009.

[34] S. M. Friedman, D. A. Mendelson, S. L. Kates, and R. M. McCann, "Geriatric co-management of proximal femur fractures: total quality management and protocol-driven care result in better outcomes for a frail patient population," Journal of the American Geriatrics Society, vol. 56, no. 7, pp. 1349-1356, 2008.

[35] Y. L. Shyu, J. Liang, C. Wu et al., "Interdisciplinary intervention for hip fracture in older Taiwanese: benefits last for 1 year," Journals of Gerontology A: Biological Sciences and Medical Sciences, vol. 63, no. 1, pp. 92-97, 2008. 


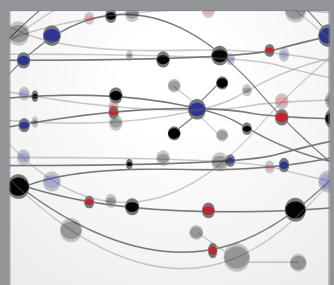

The Scientific World Journal
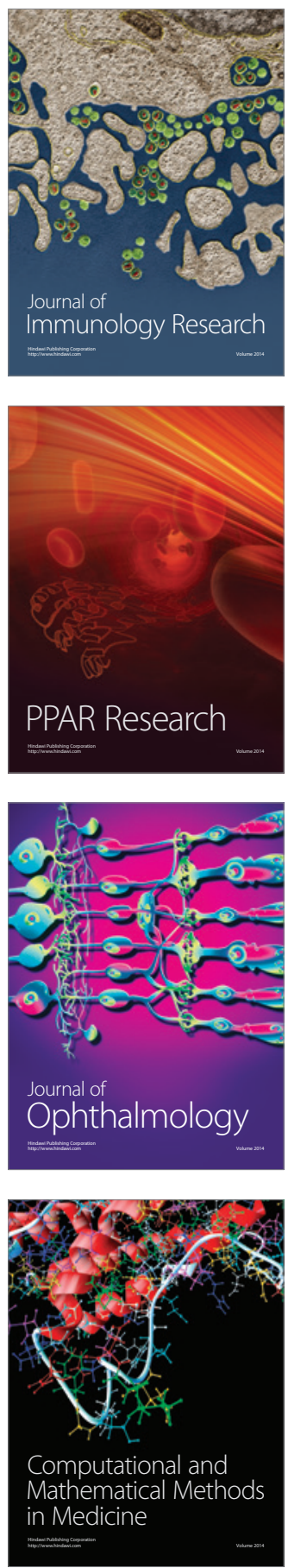

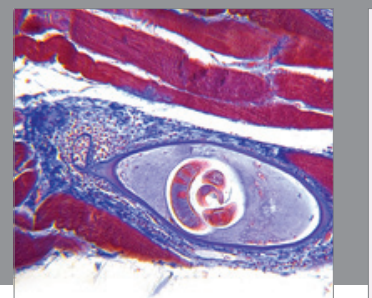

Gastroenterology

Research and Practice
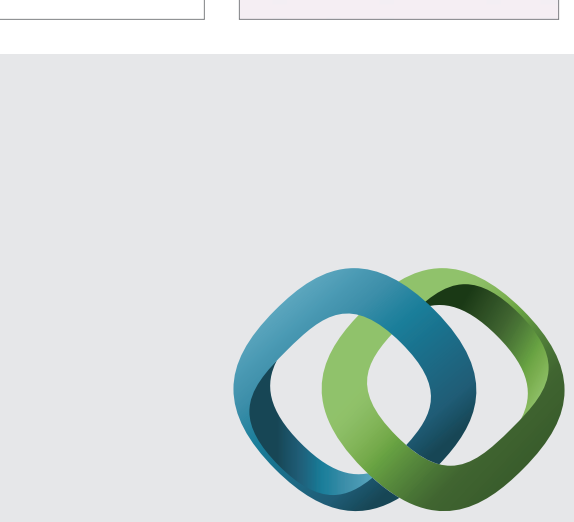

\section{Hindawi}

Submit your manuscripts at

http://www.hindawi.com
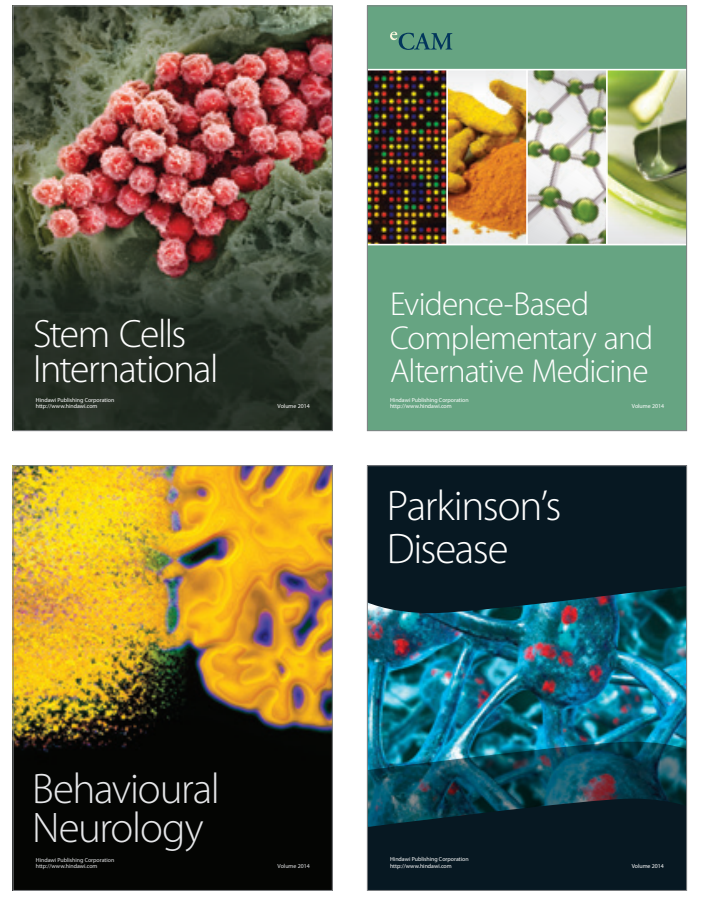
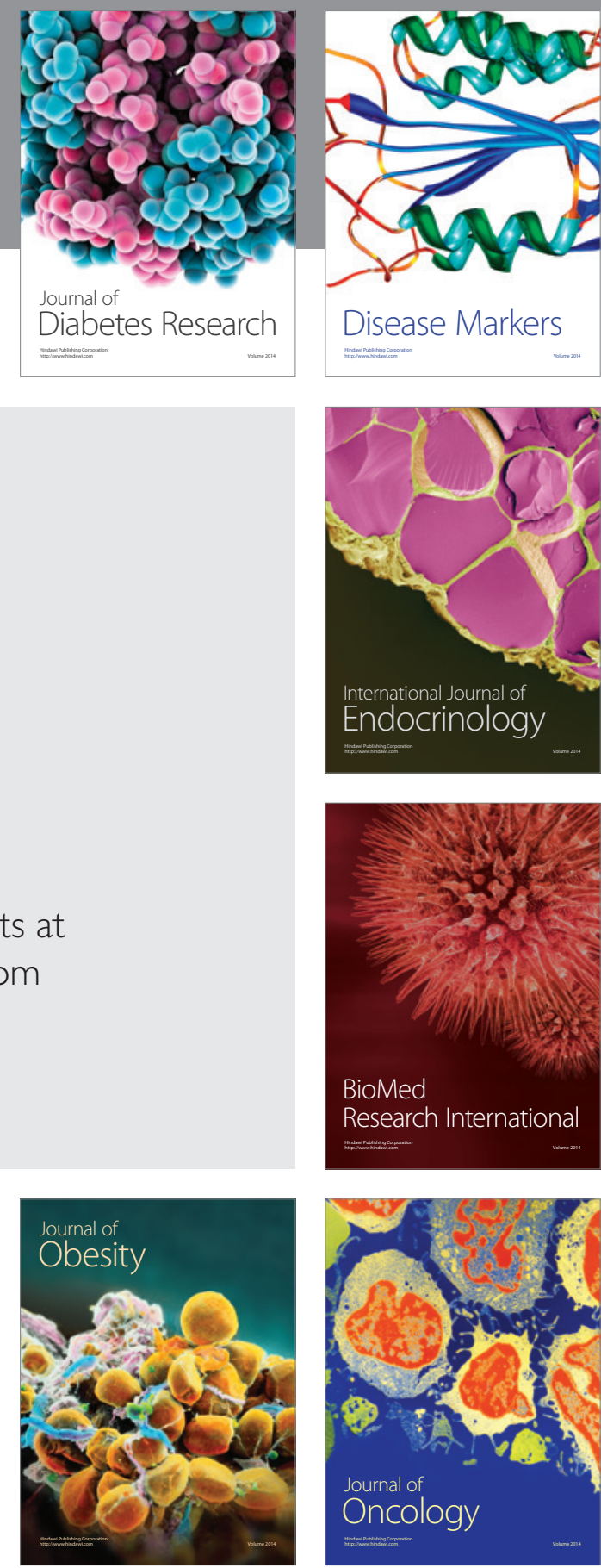

Disease Markers
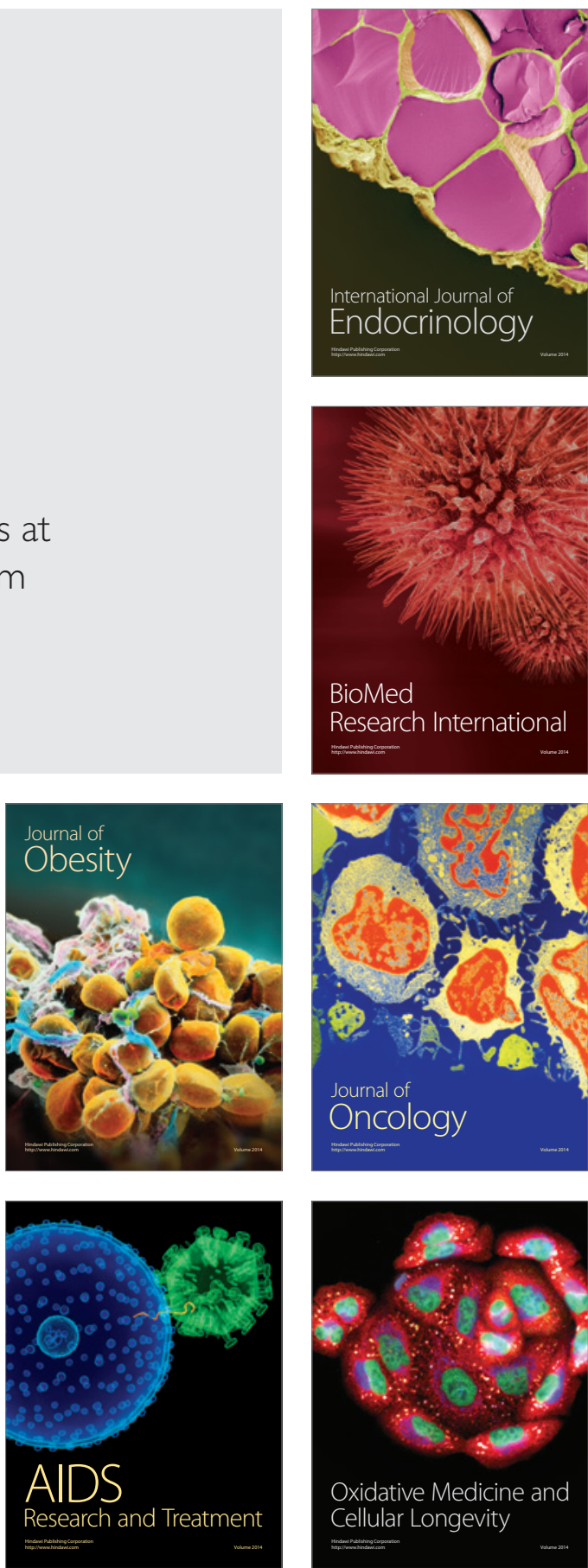